\title{
Os dois lados do AtlânTICo: DA "SElva” de FerReira de CASTro Às ILUSTRaÇões de Portinari ${ }^{1}$
}

\author{
Maria de Fátima Fontes Piazza* \\ md.piazza@uol.com.br
}

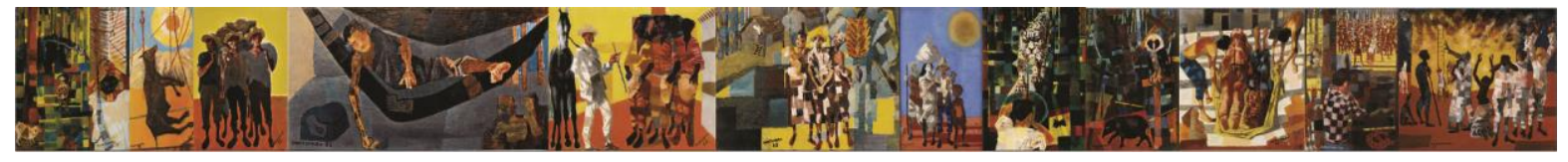

RESUMO: Este artigo tem como escopo mostrar como se deu a circulação de sensibilidades entre os dois lados do Atlântico, Brasil e Portugal, tendo como epicentro a edição de luxo de "A Selva" do escritor português Ferreira de Castro e das doze ilustrações de Cândido Portinari para esta edição, publicada em 1955, pela casa-editora Guimarães \& C ${ }^{a}$ Editores. O ponto de partida foi a análise do epistolário de Portinari que evidenciou uma troca epistolar entre diversos interlocutores, entre os quais Ferreira de Castro, Portinari e o crítico Mário Dionísio, que permitiu inferir que esta edição repercutiu no meio intelectual brasileiro e português com notas, artigos e crítica na imprensa dos dois lados do oceano e que "A Selva" é fruto da vivência do escritor português nas brenhas da floresta amazônica entre 1911 a 1914, em pleno seringal Vila Paraíso, às margens do Rio Madeira, no Estado do Amazonas, o que mostra que formou a sua sensibilidade nesta região do Brasil. Ao contrário do pintor, cujas ilustrações são conhecidas na sua obra pictórica e compõem o seu repertório cromático e de figuras humanas e animais. O caminho dessa troca cultural fez o sentido inverso do colonialismo ibérico, da ex-colônia para a ex-metrópole.

PALAVRAS-CHAVE: Portinari; Ferreira de Castro; ilustrações; sensibilidades.

Tive ontem a agradabilíssima surpresa ao chegar a casa para o almoço, de encontrar a sua magnífica oferta de um exemplar de $<<$ A Selva $>>$, na bela edição monumental acabada de sair. (...) Não falo nas ilustrações do grande Portinari porque já as conhecia da exposição na Guimarães, mas que, enquadradas na acção, fazem sentir melhor a sua grandeza. Não se pode dizer que elas valorizem o texto, porque este não o necessitava. Trata-se de duas

\footnotetext{
* Professora do Departamento de História da Universidade Federal de Santa Catarina e Doutora pelo PPGH/UFSC, com a tese "Os afrescos nos trópicos: Portinari e o mecenato Capanema".
} 
obras de arte, que se conjugam e interpenetram, mas que ficam independentes. $^{2}$

Este trecho da carta do crítico literário e dramaturgo português João Pedro de Andrade (1902-1974) apontou para uma interlocução entre o campo intelectual português e o brasileiro, especialmente, entre o pintor Cândido Portinari (1903-1962) e o escritor e jornalista José Maria Ferreira de Castro (1898-1974).

Algumas questões merecem uma reflexão para proceder a esta análise. Primeiramente, a carta estava se referindo a edição de luxo do romance $A$ Selva, de Ferreira de Castro, comemorativa ao $25^{\circ}$ aniversário da obra, publicada pela Guimarães \& $\mathrm{C}^{\mathrm{a}}$. Editores, em 1955, que estreitou as relações de amizade entre o pintor de Brodósqui e o escritor português.

Segundo, esta edição é composta de 12 ilustrações de Portinari, como: $O$ Seringueiro $^{3}$, O boi no guindaste ${ }^{3}$, Os Brabos ${ }^{4}$, Rede $^{5}$, A inspeção $^{6}$, A Clareira ${ }^{7}$, Os retirantes $^{8}$, A Onça $^{9}$, O Cemitério $^{10}$, O Índio Morto ${ }^{11}$, Os Índios ${ }^{12}$ e $O$ incêndio $^{13}$. As ilustrações não ficaram restritas ao público-leitor do livro, os originais foram expostos em Lisboa, na sede da casa-editora Guimarães \& C $C^{a}$. Editores, na Rua da Misericórdia $n^{\circ} 68$, em maio de 1955, com apresentação do escritor e pintor Almada Negreiros e na cidade do Porto, na galeria da Academia Dominguez Alvarez, na Rua da Alegria $\mathrm{n}^{\circ} 171$ - $1^{\circ}$, que então pertencia ao pintor Jaime Isidoro (1924-2009) e na abertura do vernissage contou com breve palestra do escritor António Ramos de Almeida, sob o título "Ferreira de Castro e Portinari na cultura luso-brasileira", que ocorreu entre os dias 13 a 18 de outubro de 1955 . O que lhe rendeu inúmeros artigos e notas na imprensa portuguesa, com Abel Manta, Mário Dionísio, entre outros.

Finalmente, a escolha de Portinari para ilustrar esta edição de A Selva prende-se ao conhecimento da sua obra pelo campo intelectual português, desde 1940 quando Café integrou o Stand de Arte do Pavilhão do Brasil na Exposição do Mundo Português e que repercutiu com discussões em torno de questões centrais da arte moderna (LEHMKUHL, 2011). Apesar dessa repercussão, a análise de Luciene Lehmkuhl apontou que Portinari "só foi verdadeiramente recuperado pelos neorrealistas" em Portugal, após a exposição Portinari, no outono de 1946, na Galerie Charpentier, em Paris, que provocou uma grande polêmica no campo da esquerda entre Roger Garaudy, Pierre Hervé e Louis Aragon, que encetou a segunda "querelle du réalisme" e despertou o interesse do crítico Mário Dionísio [de Assis Monteiro] (1916-1993), que entrevistou o pintor e publicou na revista Vértice (v. II, n. 30/31, 
maio de 1946). ${ }^{14}$ Convém ressaltar que, a entrevista de Portinari publicada na Vértice saiu do prelo cinco meses antes da exposição em Paris.

O ápice da trajetória de Portinari em Portugal foram as 12 ilustrações da edição comemorativa de A Selva (1955), a exposição das ilustrações em Lisboa e no Porto e a crítica de arte de Mário Dionísio que culminou com o álbum Portinari (Lisboa: Artis, 1963, que contém 51 reproduções $\mathrm{P} \& \mathrm{~B}$ e 5 à cores) e com a conferência Mes souvenirs d'un grand peintre: Hommage à Cândido Portinari (Paris: Fundação Calouste Gulbenkian/Centre Culturel Portugais, 1988).

Uma carta de Mário Dionísio para o pintor permite vislumbrar o impacto que as ilustrações causaram no campo intelectual português, além de revelar o seu encantamento com as ilustrações de Portinari e o seu desejo de estudar o pintor. Assim se expressou o crítico português:

Os recortes que o Ferreira de Castro lhe enviou dão-lhe a medida do interesse que as ilustrações aqui despertaram. Infelizmente, a minha vida profissional não me deixou deslocar ao Porto para assistir, como estava previsto, à inauguração da exposição. Mas sei que os visitantes faziam bicha à entrada e que o Ferreira de Castro autografou dezenas de catálogos. Vi a transcrição do meu pequeno texto num jornal daí, o "Correio da Manhã". E fico satisfeito de saber que ele lhe agradou. O meu plano de escrever um pouco mais demoradamente sobre a sua pintura não desapareceu ${ }^{15}$.

Como se depreende pelo excerto da carta, a crítica de Mário Dionísio reverberou do outro lado do Atlântico, no prestigiado jornal Correio da Manhã, no Rio de Janeiro. Através do epistolário do pintor, vislumbra-se a formação de uma importante rede de sociabilidade intelectual que se espraiou pelos dois continentes, inclusive a crítica do escritor português era um argumento de autoridade que passou a ter influência no campo intelectual português e brasileiro.

A presente comunicação tem como escopo mostrar a importância do Brasil: da terra e do homem, no processo de formação da sensibilidade do romancista Ferreira de Castro, que começa em 1911, quando chegou ao seringal Vila Paraíso no Estado do Amazonas durante o declínio da "febre da borracha" para trabalhar nas piores condições subumanas como emigrante na extração do látex. A importância do Brasil na obra do escritor português pode ser constatada na narrativa dos seus romances Emigrantes (1928) e A Selva (1930).

A questão das sensibilidades tem o sentido atribuído por Sandra Jatahy Pesavento que a encara como "uma aventura da individualidade que se encontra no centro das ambições da história cultural”. Para a historiadora, a dificuldade de apreensão das sensibilidades está nas sutis manifestações que "se inscrevem sob o signo da alteridade, traduzindo emoções, 
sentimentos e valores que não são mais os nossos". O que a "sensibilidade consegue, pela evocação ou pelo rememorar de uma sensação [por imagens, lembranças ou experiências], reproduzir a experiência do vivido, reconfigurado pela presença do sentimento". (PESAVENTO, 2007, pp. 9-21)

Daí, a questão central: O livro A Selva pode ser lido como um gênero autobiográfico, fruto da sensibilidade de Ferreira de Castro forjada nas imagens, lembranças ou experiências vividas no "cárcere verde" nas brenhas da floresta amazônica brasileira?

A Selva, romance publicado em 1930, tem uma narrativa autobiográfica, que contempla a região amazônica com uma descrição minuciosa de seus rios e afluentes, da sua população ribeirinha composta de indígenas e caboclos, dos retirantes da seca nordestina, especialmente, os maranhenses e cearenses, que se submetiam ao trabalho escravo nas entranhas da selva amazônica, dos emigrantes estrangeiros sujeitos ao mesmo regime de trabalho e ao sistema de barracão, dos ataques indígenas, entre muitas outras questões. O que demonstra que esta obra seguiu o rumo do romance moderno, com influência do naturalismo/realismo de Émile Zola e de Máxim Gorki (pseudônimo de Alexei Maximovitch Peshkov [1868-1936]), no que se refere à questão social e aos excluídos e as suas trágicas existências.

Os romances Emigrantes e A Selva são de denúncia social, nos dois narrou a sua "longa aventura" do outro lado do Atlântico e mostrou o "drama da emigração". Entretanto, Emigrantes, publicado em 1928, é cronologicamente, a primeira obra de literatura de sentido social que apareceu em língua portuguesa, chamou à atenção "contra os que no Brasil e em Portugal exploram o emigrante, contra os que fazem de uma enormíssima legião de homens ingênuos uma montanha de destroços, de farrapos, de vencidos", como apontou o escritor Humberto de Campos. Face à repercussão dessa obra, o romance foi muito lido e discutido no Brasil e em Portugal, inclusive suscitou polêmicas com laivos nacionalistas e foi traduzido para o italiano, o espanhol e o russo ${ }^{16}$.

Em A Selva narra a saga do um emigrante português Alberto no seringal Vila Paraíso, localizado no município de Humaitá, às margens do Rio Madeira, no Estado do Amazonas, no coração da selva amazônica, no período do declínio da "febre da borracha", com toda a carga dramática que a condição subumana de um trabalhador braçal pode ser descrita, agravada pela condição de emigrante português, em que eram recrutados sempre com a esperança de fazerem fortunas, como nessa passagem:

\footnotetext{
- Para o Rio Madeira, disse o tio?

- É. O seringal chama-se o Paraíso.
} 
(...) Que é que eu iria fazer lá?

- O que irias fazer?... Não sei. Cortar seringa, talvez não, porque é duro. Mas os seringais têm sempre um escritório, um armazém...Vamos a ver. Vamos a ver o que se arranja. E não te aborreças, pois aquilo, para quem tem sorte e juízo, são terras onde se enriquece em pouco tempo. (FERREIRA DE CASTRO, 1982, pp. 33-34)

Além disso, a narrativa acentua o caráter ingênuo do emigrante, a esperteza dos agenciadores em Portugal, a selva longe dos ecos da civilização e a lenda das fortunas acumuladas:

Não o atraíam esses rios de lendárias fortunas, onde os homens se enclausuravam do Mundo, numa confrangida labuta para a conquista do oiro negro, lá onde os ecos da civilização, só chegavam muito difusamente, como de coisa longínqua, inverossímil quase. (...) Era, então a Amazónia um imã na terra brasileira e para ela convergiam copiosas ambições dos quatro pontos cardeais, porque a riqueza se apresentava de fácil posse, desde a audácia se antepusesse aos escrúpulos. Com os rebanhos, idos do sertão do Noroeste, demandavam a selva exuberante todos os aventureiros que buscam pepitas de oiro ao longo dos caminhos do Mundo. E como não era na brenha espessa que se encontrava, para os ligeiros de consciência, a aurífera jazida, quedavam-se os ladinos em Belém e Manaus, a traficar com o esforço mitológico dos que, entre todos os perigos, se entregavam à extracção da borracha. Fora assim que seu tio enriquecera e tinha já duas quintas em Portugal; fora assim que pobretões sem eira nem beira se transformaram, de um instante para o outro, em donos de "casas aviadoras", tão poderosas que sustentavam no dédalo fluvial grande frota de <<gaiolas〉>. (FERREIRA DE CASTRO, 1982, pp. 3435)

Ferreira de Castro narra a partir da chegada do navio "Justo Chermont", conhecido naquela região como "gaiola", a entrada na floresta tropical luxuriante:

(...) seguia entre duas margens - terra baixa, terra em formação, arrastada das cabeceiras e detida ali, partícula a partícula, ora a esconder-se na água, ora ao expor ao sol a sua capa de lama, submissa à vontade das marés. Cobri-a densa vegetação, que se entrelaçava, dir-se-ia com frenesi, numa ciclópica muralha de troncos, ramos e folhas. Eram miríades de variedades, roubando-se mutuamente o carácter, confundindo-se fraternizando em abracadabrante luxúria vegetal. Árvore que pretendera desgrenhar a cabeleira mais acima da das irmãs, fora seguida por tão copiosa multidão de lianas e parasitas, que dentro em pouco o seu desejo se tornara vaidade inútil. Quase não se vislumbravam os caules: as plantas rasteiras, os arbustos, os <<tajás〉> e os cipós, tudo ocultavam, tudo fechavam, inexoravelmente. (FERREIRA DE CASTRO, 1982, p. 49)

O romance permite mostrar que a sensibilidade do escritor foi forjada em plena adolescência entre 1911 a 1919, na região norte do Brasil. Viveu entre 1911 a 1914, em pleno seringal Vila Paraíso e entre 1914 a 1919, nas cidades de Belém do Pará e Manaus, onde exerceu diversos ofícios para sobreviver, entre os quais o de escritor e de jornalista, fundou o semanário Portugal (1917), colaborou nos jornais A Cruzada e no Jornal dos Novos até que 
conseguiu publicar em fascículos o seu primeiro romance Criminoso por ambição (Belém do Pará: Typ. F. Lopes, 1916), escrito aos quatorze anos de idade.

Pela sua vivência no "coração das trevas" - numa alusão ao romance de Joseph Conrad -, que a sua narrativa é carregada com toda a força dramática, além da influência que a terra e o homem brasileiros tiveram na construção da sua percepção/sensibilidade sobre aquela região do país. Daí a grandiloquência com que trata a natureza, numa aproximação com a "estética romântica do sublime":

(...) naquilo em que o romantismo se aproxima da expressão artística da ruína, do sombrio, da decadência, dos horrores grandiosos, paradoxalmente terríveis e agradáveis: no "Preâmbulo" à obra $O$ inferno Verde, romance de Alberto Rangel, de 1907, que tem como cenário a Amazônia, e referindo-se especificamente a ela, Euclides da Cunha nos dá conta dessa impossibilidade de conhecimento da floresta tropical, da sua magia e magnificência, do assombro que provoca, mesclando temor e curiosidade. (NAXARA, 2004. p. 29)

Ferreira de Castro conheceu in loco esta realidade, povoada de mazelas sociais, com um sistema de trabalho muito próximo ao da escravidão recém-extinta (1888) e com o sistema do "barracão", no qual migrantes (retirantes nordestinos, especialmente fugindo da grande seca de 1898) e emigrantes dependiam do patrão e ficavam subjugados a ele, desde a compra de alimentos até de remédios, sem jamais saldar a dívida do armazém. Este sistema era perverso, porque, algumas vezes, o pagamento era feito em mercadorias e o trabalhador comprava no barracão do proprietário a preços altos e tinha o valor descontado no salário. Como conta a personagem Firmino:

Eu tenho estado sempre a dever. Não há maneira de me livrar daquela conta! Quando seu Alípio foi ao Ceará buscar pessoal, me disse que um homem enriquecia logo que chegava aqui. Eu acreditei naquelas lorotas e, afinal, ainda não paguei a passagem. (...) Vendem tudo muito caro, que é para o seringueiro não arranjar saldo e ficar toda a vida nestas brenhas do diabo. (FERREIRA DE CASTRO, 1982, p. 112)

É deste lado do oceano que o romancista português amalgamou a sua sensibilidade, como pode ser constatado na sua narrativa sobre a terra brasileira, especialmente, a Amazônia acima descrita. Ao contrário, podemos constatar que o pintor não dependeu exclusivamente da narrativa de Ferreira de Castro para compor as personagens das doze ilustrações que compõem esta edição do romance $A$ Selva. O caminho dessa troca cultural fez o sentido inverso do colonialismo ibérico, da ex-colônia para a ex-metrópole. 


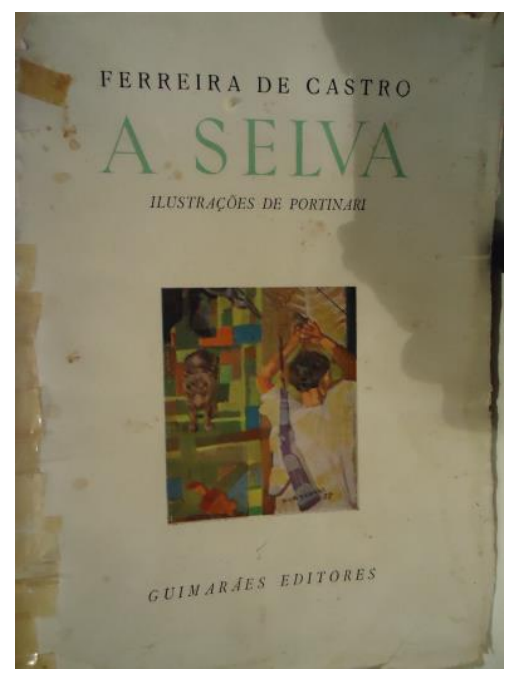

Esta edição de luxo, que é nosso objeto de estudo ${ }^{17}$, mostrou que as ilustrações são povoadas de personagens que compõem o universo portinariano, como os retirantes, os índios, os mestiços, os trabalhadores, os animais, entre outros. Sendo que a crítica costuma apontar "os retirantes" como o ponto de convergência da pintura de Portinari e A Selva de Ferreira de Castro, inclusive Mário Dionísio o cognominou de "pintor de camponeses"18.

Convém ressaltar que estas ilustrações são contemporâneas aos painéis Guerra e $\mathrm{Paz}^{19}$ do prédio da ONU, em Nova York, como revelou o pintor em carta. Também, mostrou o seu empenho e zelo na feitura das ilustrações e o seu talento como artista gráfico:

Com imenso prazer recebi sua carta e parei todos os meus trabalhos, inclusive os 2 painéis para a sede da O.N.U. em Nova York (14 ms x 10) cada um, para entrar na "A Selva". Grande livro - como o próprio Amazonas. (...) A sobriedade de colorido nos desenhos lhes dará mais atmosfera. Talvez possa em certas ilustrações usar o cinza e apenas substituir o vermelho sanguínea por verde esmeralda. Tendo as ilustrações praticamente uma só côr, isso importa uma grande economia, devendo-se entretanto cuidar especialmente em conseguir todas as nuances de preto e branco, exatamente como nos originais. Estou the mandando um pequeno desenho da amostra. Como pode ver há várias nuances de cinza e vermelho, cores usadas pelos nossos indígenas em sua arte. Os originais medem, mais ou menos, 30 x 40 c. Seria bom que nos clichês se conservasse a margem branca na proporção da pequena amostra que aqui lhe envio. O papel que estou usando para o nosso trabalho é F. Perrigot, Archer Especial; o lápis Faber comum e sanguínea ${ }^{20}$.

Quanto às ilustrações apresentadas, Portinari buscou na sua obra as personagens para compor as doze ilustrações de A Selva, sendo os retirantes a pièce de resistánce.

Convém salientar que, a Série Retirantes composta de Retirantes $^{21}$, Criança Morta $^{22}$ e Enterro na Rede ${ }^{23}$ foi sempre apontada pela crítica de arte como o auge da fase social do pintor, inclusive mobilizou a intelectualidade francesa e a portuguesa, sendo que a primeira, com a "querelle du réalisme" (depois da exposição da Galerie Charpentier, com 
mais de 80 obras, entre as quais a Série Retirantes) e a segunda, com o "neo-realismo". Estas obras convergem para a discussão no campo intelectual do sentido social da arte, do humanismo, do realismo e da consciência política no meio artístico. Poder-se-ia dizer que na década de 1940, o campo intelectual caminhou pari passu com o campo político. Esta série repleta de cenas pungentes e dramáticas, onde Portinari usou o léxico picassiano da gramática cubista (leia-se: Guernica de Pablo Picasso), que mobilizou grande parte da intelectualidade européia recém-saída da Guerra Civil Espanhola e da Segunda Guerra Mundial, com imagens de êxodos, crianças mortas, mulheres chorando, seres humanos famélicos, maltrapilhos e andrajosos.

Entretanto, como chamou à atenção Annateresa Fabris (2011, p. 36):

O fato de haver uma relação quase especular entre Portinari e Picasso não deve fazer perder de vista um dado fundamental: boa parte da visualidade do modernismo brasileiro está sob o signo da volta à ordem.

Também, ressaltou que Portinari

(...) para atingir o Brasil como um todo em cenas cujo ator principal é frequentemente o trabalhador. Seu realismo, alimentado pelas gramáticas da volta à ordem, abebera-se, nesse momento, na lição realista do século XIX, que condensava na figura do trabalhador uma série de fatores: injustiça social, dignidade, heró́smo e probidade do trabalho manual. $\mathrm{O}$ fato de experimentar "todos os processos de pintar, não só já no sentido superior da técnica, como do próprio artesanato" [Mário de Andrade - O Baile das quatro artes, p. 124] faz dele o próprio emblema do artista-artesão, do trabalhador que acredita na dignidade do trabalho manual e, que, por isso mesmo, não se esquece das exigências sociais da arte. (FABRIS, 2011, pp. 35-36)

Nos estudos do painel Guerra constatou-se uma série de figuras humanas e de animais, como por exemplo: Feras ${ }^{24}$ onde é possível perceber que estas figuras e a escala cromática que a compõe são as mesmas da ilustração $A$ onça e que foram feitas simultaneamente ao do painel da ONU. Também, no tríptico Floresta ${ }^{25}$ e no painel Desbravamento da Mata $^{26}$ é possível identificar as figuras de animais que povoam as 12 ilustrações de A Selva.

Convém ressaltar que, apesar da obra portinariana assinalar para a presença destas figuras humanas e animais, uma carta de Ferreira de Castro para o pintor revelou que ambos estavam envolvidos no projeto editorial e na perspectiva de que a qualidade gráfica e tipográfica da obra ficasse à altura das suas expectativas. O escritor preocupado com a composição das ilustrações indicou uma obra e um acervo a ser pesquisado, daí a pergunta à Portinari: 
Se V. precisar de alguns elementos sobre o Amazonas, encontra-los-à, na dúvida, no Serviço de Proteção aos Índios, que funciona no Rio de Janeiro. Há mesmo uma brochura intitulada "Pacificação dos Parintintins", de Joaquim Gondim. Além disso, não lhe faltarão aí volumes com fotografias sobre seringueiros, as suas barracas, etc. Por outro lado, eu fico inteiramente ao seu dispor, para o caso de precisar algum esclarecimento da minha parte ${ }^{27}$.

Se esta indicação ajudou na composição das ilustrações ainda não se sabe, mas o pintor pode ter se respaldado em outras sugestões. Apesar de Portinari ser muito independente nas suas escolhas e as 12 ilustrações de A Selva revelam muito do cromatismo e da composição do painel Guerra.

O impacto das ilustrações de Portinari para a edição de luxo de $A$ Selva foi tão estrondoso que reverberou nos dois lados do Atlântico, ao ponto do escritor português Aquilino Ribeiro escrever para Portinari propondo que ilustrasse D. Quixote para a casaeditora da Livraria Bertrand, traduzida por ele ${ }^{28}$ e a casa-editora Saraiva S/A Livreiros, de São Paulo, fez uma proposta em 1958, para lançar uma edição brasileira de A Selva, reproduzindo as mesmas ilustrações como se depreende da troca epistolar entre o escritor português e o pintor brasileiro ${ }^{29}$.

Os painéis Guerra e Paz são apontados como o coroamento da carreira de Portinari - como assinalou Israel Pedrosa - eles foram gestados num mundo em transformação, com a população vivendo as consequências da catástrofe da Segunda Guerra Mundial, com a guerra fria dividindo o mundo entre socialismo e capitalismo, com os intelectuais de esquerda alinhados na "Campanha pela Paz", cujo símbolo era a pomba desenhada por Picasso. Portinari seguia seu engajamento político nas hostes do Partido Comunista Brasileiro (PCB), tinha exposto seus trabalhos na Galerie Charpentier, em Paris e provocado a segunda "querelle du réalisme", que envolveu o campo da esquerda, notadamente o Partido Comunista Francês $(\mathrm{PCF})^{30}$.

Por isso, a pergunta que não quer calar: Seria Ferreira de Castro um neo-realista?

A resposta é dada por um estudioso da sua vida e obra, que afirmou que o escritor é de difícil classificação. Segundo Ricardo António Alves (2002, p. 73-74)

De duas, uma: ou Ferreira de Castro é um escritor neo-realista, talvez não o primeiro, mas o mais consistente romancista que com Emigrantes procurou descrever a realidade, denunciando-a e propondo uma alternativa, cerca de uma década antes de Alves Redol, com Gaibéus (1939), ou, caso contrário, Ferreira de Castro não é um escritor neo-realista, sequer precursor. Dir-se-á que a primeira hipótese é absurdamente anacrônica, pois a expressão $<<$ neorealismo >>, criada por Joaquim Namorado, visava encobrir uma outra, o $<<$ realismo socialista >> e soviético. Assim entendido o neo-realismo, Castro que não foi um marxista, dificilmente aderiria aos seus pressupostos políticos. 
Pela análise de Alves, a obra de Ferreira de Castro não entra nessa classificação de um movimento marcado por características tão lusitanas. Entretanto, a obra do escritor português tem como escopo a denúncia social e, por isso, pode ter sido apropriada pelo campo intelectual português e pelas hostes de esquerda como parte de uma estética neo-realista. Convém ressaltar que Portugal vivia há décadas sob o jugo da ditadura de António de Oliveira Salazar, o que levou a censura e a cisão do campo intelectual. O que nos permite uma reflexão de que o neo-realismo coube mais no terreno das idéias e das práticas políticas do que no da literatura e das artes visuais. E, conforme um analista:

O neo-realismo foi colhido ou tolhido, com efeito, por uma adversidade a que não conseguiu eximir-se: a de a literatura ser a única expressão viável de aspectos da vida social que, noutras circunstâncias, teriam cabido ao jornalismo, à política e ao livro doutrinário. (SACRAMENTO, 1968, pp. 3031)

O próprio Mário Dionísio, reconhecido "como um dos maiores, ou o principal, teórico do neo-realismo, manifestou sempre uma posição restritiva quanto aos seus fundamentos." O crítico, durante o Estado Novo português, sempre "falava desse movimento como a representação literária de "uma ideologia que é nova entre nós" (ALVES, 2002, p. 75). O que o levou a afirmar que: "Ferreira de Castro não é um neo-realista", entretanto, "É a ele que os neo-realistas tem de agradecer para sempre o desbravar da rota". (ALVES, 2002, p. 76)

Na realidade, Ferreira de Castro tinha uma personalidade muito independente, que segundo um analista era de uma "insubornável independência". No campo político, se posicionava como um assumido opositor do regime salazarista, também não era adepto ao partido comunista, apesar de ter amigos e companheiros de ofício filiados ao PCP, pelo contrário, era defensor do anarco-sindicalismo e convicto de ideias libertárias. Segundo Alves (2002, p. 114): “(...) Proudhon, Malatesta, e principalmente os textos do príncipe revolucionário russo (Kropotkine) foram determinantes para as definições do contorno da mensagem da obra literária e libertária que nos legou".

Para este abalizado conhecedor da vida e da obra de Ferreira de Castro, o escritor foi

representante maior duma corrente de pensamento libertária - e minoritária na literatura portuguesa, Ferreira de Castro foi, no fundo, autor de si próprio. É essa singularidade num escritor tão popular, paradoxalmente com um percurso ideológico quase solitário, que exerce um fascínio acrescido pela sua personalidade e pela sua obra. (ALVES, 2002, pp. 161-162) 
Poder-se-ia dizer que o escritor português não pertenceu nem ao primeiro modernismo português ligado à revista Orpheu: Revista Trimestral de Literatura - Portugal e Brasil (1915), com Fernando Pessoa, Mário de Sá Carneiro, António Ferro, Luís de Montalvor, entre outros e nem ao segundo modernismo ligado à revista Presença: Folha de Arte e Crítica (1927-1940), que esteve sob a direção de Branquinho da Fonseca, João Gaspar Simões e José Régio, não foi um "neo-realista" conforme acentuou Mário Dionísio, entretanto, colaborou com a revista do grupo que se intitulava Vértice (vide: nota $\mathrm{n}^{\circ}$ 17). Pelo seu epistolário depreende-se que os seus interlocutores eram de diversas tendências estéticas e políticas, abrangendo um amplo espectro, de João de Barros, João Lúcio de Azevedo, Fidelino de Figueiredo até Mário Dionísio, Jorge Amado, Cândido Portinari, entre muitos outros.

A troca epistolar entre Portinari e Ferreira de Castro revelou que a edição de luxo comemorativa aos 25 anos do romance A Selva, com as doze ilustrações de Portinari proporcionou um estreitamento das relações entre o campo intelectual português e o brasileiro. Como se depreende da carta de Portinari:

Meu caro Ferreira de Castro

Recebi os recortes e o aviso do banco,

Estou muito contente com o êxito do nosso trabalho. Foi feito com entusiasmo e admiração pela sua obra.

Desejava agradecer também ao Almada Negreiros [Fernando] Pamplona e a João de Barros: deste último apareceu aqui esplêndido artigo. Do Porto pediram-me permissão para exibirem ali o nosso trabalho respondi que da minha parte dou permissão contanto que consultem o querido amigo.

Já não tenho pressa em ter os originais porque pretendo mais adiante expor não somente esses mas todos os estudos.

No momento tenho trabalhado dia e noite nos murais da O. N. U. Já estou com o da $<<$ Guerra $>>$ bem adiantado. Assim que tiver fotos lhe enviarei. Não sei se da Itália lhe mandaram um álbum de desenhos que acabam de editar; é edição estupenda de 100 desenhos e 8 coloridos. Recomendações nossas para sua Senhora. Receba o abraço afetuoso e de admiração do seu

Portinari

Rio VI-55 $5^{31}$

Nos dois lados do Oceano Atlântico, Portinari e Ferreira de Castro, cada qual com o seu ofício revelaram as mazelas da sociedade brasileira, do sistema de trabalho braçal à migração e a emigração que são temas universais. O encontro entre Ferreira de Castro e Portinari se dá no sentido social da arte, daí a repercussão que o óleo sobre tela Café (1935) de Portinari causou no campo intelectual daquele país, por ocasião da Exposição do Mundo Português, em 1940, que apontou para as desigualdades sociais e raciais que marcaram indelevelmente a sociedade brasileira fruto de séculos de escravidão, tanto na referência explícita da figura do capataz (feitor) com o chicote, quanto com a representação da colona e do trabalhador braçal colhendo nos pés de café e carregando os sacos do principal produto de Maria de Fátima Fontes Piazza. Os doIS LAdOS DO ATLÂNTICO: DA "SElVA" DE FerReIRA DE CASTRO Às 
exportação do Brasil. Na narrativa de Ferreira de Castro em A Selva também, comparece o feitor, quando pontifica um diálogo do negro Tiago, como “- Eu é que sei o que é ser escravo! Ainda tenho aqui, nas costas, o sinal do chicote do feitor, lá do Maranhão. Branco não sabe o que é liberdade como negro velho. Eu é que sei” (FERREIRA DE CASTRO, 1982, p. 282).

Convém ressaltar que, tanto a obra de Portinari, quanto a de Ferreira de Castro estavam distantes da estética "neo-realista" portuguesa e do realismo egresso das hostes estalinistas. Ambos se apresentavam com um perfil muito independente e com certa distância das diretrizes e da disciplina partidária. Os críticos apressadamente os identificaram com estas linguagens artísticas, entretanto, os temas é que se aproximavam das demandas do campo intelectual ligadas às questões sociais como as trágicas existências dos trabalhadores e dos deserdados e às questões políticas com o engajamento na "Campanha pela Paz", no protesto contra as ditaduras da península ibérica, o salazarismo e o franquismo.

Concluo com uma frase de Mário Dionísio que mostra o sentido social que os dois intelectuais deram ao mundo luso-brasileiro, com esta edição de luxo do romance $A$ Selva, o pintor com o traço, a paleta e o pincel e o escritor, com a pena "Um escritor português e um pintor brasileiro estendem os braços por cima do largo oceano e misturam as suas vozes num mesmo apelo. É uma data importante para todos os que confiam no poder da beleza para construir a paz e fazer do mundo a casa dos homens" ${ }^{\prime 32}$.

\section{The two sides of The Atlantic: from the "Jungle" OF Ferreira de CaStro to PORTINARI'S ILLUSTRATIONS}

ABSTRACT: This article was designed to demonstrate how has been occurred the opinions' movement between the two sides of the Atlantic, Brazil and Portugal and the epicenter was the exclusive edition of "The Jungle" by the Portuguese writer Ferreira de Castro and twelve illustrations by Candido Portinari, published in 1955, by publishing-house Guimarães \& $\mathrm{C}^{\text {a }}$ Editors. The starting point was the analysis of the Portinari's epistolary that showed an exchange between various participants, including Ferreira de Castro, Portinari and Mario Dionisio, the critic. These interchange allowed us to infer that this issue affected the Brazilian and Portuguese intellectual milieu with notes, articles and criticism in the press on both sides of the Atlantic. Furthermore, the "The jungle" was the result of the experience of the Portuguese writer in groves of the Amazon rainforest between 1911 and 1914, in full rubber 
Paradise Village on the banks of the Madeira River in the state of Amazonas. This Brazilian region formed his susceptibility. Contrasting the painter, whose illustrations constitute the chromatic repertoire with human and animal figures, known in his pictographic work. This cultural exchange did the reversal way of Iberian colonialism, from the former colony to the former metropolis.

KEY wORDS: Portinari; Ferreira de Castro; illustrations; opinions.

\section{NOTAS}

1 Este artigo integra a pesquisa "Os dois lados do Atlântico: Portinari e o campo cultural português", e contei com a colaboração das bolsistas Aline Gabriela Klauck (PIBIC/CNPq), Camila Bergamin (PIBIC/CNPq) e Mariana Carmona Braga (bolsista-voluntária IC). Originalmente foi apresentado no Simpósio Temático "Brasil-Europa: la circularidad de conocimiento y de sensibilidades a lo largo del siglo XX", coordenado pelas Professoras Rosângela Patriota e Chiara Vangelista, no $54^{\circ}$ Congresso Internacional de Americanistas, realizado em Viena, na Áustria, em julho de 2012.

2 Carta de João Pedro de Andrade para Ferreira de Castro, datada de Lisboa, 27 out. 1955. In: ALVES, Ricardo António (Org.). 100 Cartas a Ferreira de Castro. Sintra: Museu Ferreira de Castro, 1992. p. 141.

3 Ilustração $\mathrm{n}^{\circ}$ 1: O Seringueiro (1955) pintura a óleo sobre papelão, medindo 19 x 17 $\mathrm{cm}$ (estimadas), Rio de Janeiro, assinada e datada na metade inferior à direita "Portinari 55". Coleção desconhecida.

$4 \quad$ Ilustração $\mathrm{n}^{\circ}$ 3: Os brabos (1955), pintura a óleo sobre papelão, medindo 22 x $17 \mathrm{~cm}$, Rio de Janeiro, assinada e datada no canto inferior direito "Portinari 55". Coleção particular, São Paulo.

$5 \quad$ Ilustração $n^{\circ}$ 4: Rede (1955), pintura a óleo sobre papel, medindo 12 × $23 \mathrm{~cm}$, Rio de Janeiro, assinada e datada na margem inferior à esquerda "Portinari 55". Coleção particular, São Paulo.

$6 \quad$ Ilustração $\mathrm{n}^{\circ}$ 5: A Inspeção (1955), pintura a óleo sobre papelão, medindo 17 x $23 \mathrm{~cm}$ (estimadas), Rio de Janeiro, assinada e datada no canto inferior direito "Portinari 55". Coleção desconhecida.

7 Ilustração n ${ }^{\circ}$ 6: A Clareira (1955), pintura a óleo sobre papel, medindo 18 x $26 \mathrm{~cm}$, Rio de Janeiro, assinada e datada na margem inferior à esquerda "Portinari 55". Coleção particular, São Paulo.

Ilustração $\mathrm{n}^{\circ}$ 7: Os retirantes (1955), pintura a óleo sobre madeira, medindo 23 x 14,5 $\mathrm{cm}$, Rio de Janeiro, assinada e datada no canto inferior esquerdo "Portinari 55". Coleção particular, Rio de Janeiro.

Ilustração $\mathrm{n}^{\circ}$ 8: A Onça (1955), pintura a óleo sobre papelão, 21 x $17 \mathrm{~cm}$ (estimados), Rio de Janeiro. Coleção desconhecida.

10 Ilustração $\mathrm{n}^{\circ}$ 9: $O$ Cemitério (1955), pintura a óleo sobre papel, medindo 22 x 16,6 cm, Rio de Janeiro. Coleção particular, São Paulo. 
11 Ilustração no 10: $O$ Índio Morto (1955), pintura a óleo sobre papel, medindo 18 x 17 $\mathrm{cm}$, Rio de Janeiro, assinada e datada no canto inferior direito "Portinari 55". Coleção particular, São Paulo.

Ilustração no 11: Os Índios (1955), pintura a óleo sobre papel, medindo 19,2 x $15 \mathrm{~cm}$, Rio de Janeiro, assinada e datada na margem inferior esquerda "Portinari 55". Coleção particular, São Paulo.

13 Ilustração $\mathrm{n}^{\circ}$ 12: $O$ Incêndio (1955), pintura a óleo sobre papel, medindo $18 \mathrm{x} 23 \mathrm{~cm}$ (estimadas), Rio de Janeiro, assinada e datada na metade inferior esquerda "Portinari 55". Coleção desconhecida.

14 Id., p. 23-24. Vértice: Revista de Cultura e Artes, criada em Coimbra, em 1942, tendo como diretores Carmo Vaz e Raul Gomes, acompanhou o neo-realismo e seus desdobramentos. Dentre seus colaboradores de diversas tendências, destacam-se Cardoso Pires, Augusto Abelaira, Ferreira de Castro, Sidónio Muralha, Eduardo Lourenço, Fernando Namora, Joaquim Namorado, Mário Dionísio, Jorge de Sena, Mário Cesariny, Vitorino Nemésio, Afonso Duarte.

15 Carta de Mário Dionísio para Portinari, datada de Lisboa, 20 dez. 1955. CO-15781/Projeto Portinari. O artigo está sob o título Panorama Internacional: Portinari em Portugal, que saiu na edição de 4 de novembro de 1955, no Correio da Manhã, no Rio de Janeiro.

16 BRAZIL, Jaime et allii. Vários estudos de Ferreira de Castro e a sua obra. Com uma biografia inédita por Jaime Brazil. Porto: Livraria Civilização, s. d. p. 110-111.

BRASIL, Jaime. Ferreira de Castro. Lisboa: Arcádia, 1961. p. 41 (Col. A obra e o homem, v. $5)$.

17 FERREIRA DE CASTRO, José Maria. A Selva: romance; il. de Cândido Portinari; vinhetas de Roberto Nobre. Lisboa: Guimarães Editores, 1955. 322 p. il. [pranchas, mapas, facsímiles 27 x $20 \mathrm{~cm}$.]

18 Dionísio, Mário. Portinari, Pintor de camponeses. In: Vértice. Coimbra, v. II, n. 30/31, mai. 1946. p. 150-155.

19 Guerra (1952-1956), painel a óleo sobre madeira compensada, medindo 1400 x 1058 $\mathrm{cm}$. (aproximada e irregular), Rio de Janeiro, RJ. Assinado e datado no canto inferior esquerdo <<Portinari Rio 1952-1956>>, coleção da United Nations (ONU), New York, USA. Paz (1952-1956), painel a óleo sobre madeira compensada, medindo $1400 \mathrm{x} 953 \mathrm{~cm}$. (aproximada e irregular), Rio de Janeiro, RJ. Assinado e datado no canto inferior esquerdo <<Portinari Rio 1952-1956>>, coleção da United Nations (ONU), New York, USA.

20 Carta de Cândido Portinari para Ferreira de Castro, datada do Rio de Janeiro, 8 fev. 1955. CO-4417/Projeto Portinari.

21 Retirantes (1944), painel a óleo sobre tela, medindo 190 x $180 \mathrm{~cm}$., Petrópolis-RJ. Assinada e datada no canto inferior direito <<Portinari 944>>, coleção MASP/SP. Projeto Portinari/RJ.

22 Criança Morta (1944), painel a óleo sobre tela, medindo 180 x 190 cm., Petrópolis-RJ. Assinada e datada no canto inferior direito << Portinari 944>>, coleção MASP/SP. Projeto Portinari.

23 Enterro na Rede (1944), painel a óleo sobre tela, medindo 180 x 220 cm., PetrópolisRJ. Assinada e datada no canto inferior direito <<Portinari 944>>, coleção MASP/SP. Projeto Portinari.

24 Feras (1955), pintura a óleo sobre madeira compensada, medindo 159 x $220 \mathrm{~cm}$. Cf. PORTINARI, João Cândido. (Coord.). Guerra e Paz: Portinari. Rio de Dom Quixote/Projeto Portinari, 2011. p. 50-97.

25 O tríptico Floresta é composto de Floresta I (1938), painel a óleo sobre tela, medindo 159 x $139 \mathrm{~cm}$, Rio de Janeiro, RJ. Assinado e datado no canto inferior direito <<C. Portinari 
1938>>, coleção particular Rio de Janeiro; Floresta II (1938), painel a óleo sobre tela, medindo 159 x $139 \mathrm{~cm}$, Rio de Janeiro, RJ. Assinado e datado no canto inferior direito $<<\mathrm{C}$. Portinari 1938>>, coleção particular Rio de Janeiro; Floresta III (1938), painel a óleo sobre tela, medindo 159 x $139 \mathrm{~cm}$, Rio de Janeiro, RJ. Assinado e datado no canto inferior direito $<<$ C. Portinari 1938 >>, coleção particular Rio de Janeiro.

26 Desbravamento da Mata, pintura mural a têmpera/técnica e suporte combinados, medindo 316 x 431 cm., Washington DC, USA, assinada e datada no canto inferior esquerdo <<Portinari 1941〉>, coleção Library of Congress, Washington (USA).

27 Carta de Ferreira de Castro para Cândido Portinari, datada de Lisboa, 11 fev. 1955. CO-1190/Projeto Portinari.

28 Carta de Aquilino Ribeiro para Cândido Portinari, datada de Lisboa, 1 mar. 1959. CO5083/Projeto Portinari. Portinari já tinha feito 22 desenhos de D. Quixote, entre 1955 e 1956, atendendo a um convite do editor José Olympio que não chegou a publicá-los, estes desenhos foram adquiridos pelo colecionador Raymundo Ottoni de Castro Maya e pertencem a Coleção Castro Maya, no Museu da Chácara do Céu, no Rio de Janeiro. In: FABRIS, Annateresa. O artista. In: BAPTISTA, Anna Paola et allii. Portinari na coleção Castro Maya. São Paulo: Pinacoteca do Estado de São Paulo, 2010. p. 72.

29 Carta de Ferreira de Castro para Cândido Portinari, datada de Lisboa, 1 set. 1958. CO1202/Projeto Portinari; Carta de Ferreira de Castro para Cândido Portinari, datada de Lisboa 20 jul. 1958. CO-1204/Projeto Portinari; Carta de Ferreira de Castro para Cândido Portinari, datada de 19 nov. 1958. CO-1205/Projeto Portinari.

30 Sobre a "querelle du réalisme", vide: PIAZZA, Maria de Fátima Fontes. Arte \& Política: Portinari e a estética realista. Campinas: $7^{\circ}$ Encontro Internacional da ANPHLAC, 2006. http://www.anphlac.org./upload/anais/encontro7/fatima.pdf

31 Carta de Cândido Portinari para Ferreira de Castro, datada jun. 1955 [Selo dos Correios de 14 jun. 1955]. In: ALVES, Ricardo António (Org.), 100 cartas a Ferreira de Castro. Sintra: Câmara Municipal de Sintra/Gabinete de Estudos Históricos e Documentais/Museu Ferreira de Castro, 1992. p. 139.

32 DIONÍSIO, Mário. Portinari, grande ilustrador. [s.n.t.]. PR-3991.01.01/Projeto Portinari.

\section{REFERÊNCIAS BIBLIOGRÁFICAS}

ALVES, Ricardo António (Org.). 100 Cartas a Ferreira de Castro. Sintra: Câmara Municipal de Sintra/Museu Ferreira de Castro, 1992.

Anarquismo e neo-realismo: Ferreira de Castro nas encruzilhadas do Século. Lisboa: Âncora Editora, 2002.

ARAUJO, Marcelo Mattos et allii. Portinari na Coleção Castro Maya. São Paulo: Pinacoteca do Estado de São Paulo, 2010.

BAZE, Abrahim. A saga de um imigrante português. Manaus: Tvlar/Editora Valer, 2004. 
BRAZIL, Jaime et allii. Vários estudos sobre Ferreira de Castro e a sua obra: com uma biografia inédita por Jaime Brazil. Porto: Livraria Civilização, s.d. Ferreira de Castro. Lisboa: Editora Arcádia, 1961.

BRAGA, Robério. O Amazonas ao tempo de Ferreira de Castro. Manaus: Secretaria de Estado da Cultura, 2006.

CARDOSO, Joaquim. Ferreira de Castro desmascarado: a verdade acêrca do romance “Emigrantes”. Lisboa: Livraria Renascença, 1953.

FABRIS, Annateresa (Org.). No ateliê de Portinari: 1920-45. São Paulo: Museu de Arte Moderna (MAM), 2011.

FERREIRA DE CASTRO, José Maria. Emigrantes. Lisboa: Portugália Editora, 1966. A Selva. Lisboa: Guimarães \& Cia. Editores, 1982. . Forêt Vierge. Traduction de Blaise Cendrars. Paris: Bernard Grasset, 1963.

GOBBI, Márcia Valéria Zamboni. Ferreira de Castro: dizer de novo ou dizer o novo? In: ; FERNANDES, Maria Lúcia Outeiro; JUNQUEIRA, Renata Soares (Orgs.). Intelectuais portugueses e a cultura brasileira. São Paulo: Editora UNESP; Bauru: EDUSC, 2002. p. 189-201.

LEHMKUHL, Luciene. O Café de Portinari na Exposição do Mundo Português: modernidade e tradição na imagem do Estado Novo brasileiro. Uberlândia: Edufu, 2011.

LISBOA, Eugénio. $O$ Segundo modernismo em Portugal. Lisboa: Livraria Bertrand/Ministério da Educação, 1984.

NAXARA, Márcia Regina Capelari. Cientificismo e Sensibilidade Romântica: em busca de um sentido explicativo para o Brasil no século XIX. Brasília: Editora da UNB, 2004.

PESAVENTO, Sandra Jatahy. Sensibilidades: escrita e leitura da alma. In: LANGUE, Fréderique (Orgs.). Sensibilidades na história: memórias, singularidades e identidades sociais. Porto Alegre: Editora da UFRGS, 2007.

PORTINARI, João Cândido (Coord.). Guerra e Paz: Portinari. Rio de Janeiro: Dom Quixote/Projeto Portinari, 2011. . (Coord.). Catálogo Raisonné. Rio de Janeiro: Projeto Portinari, 2004. 
QUADROS, António. O primeiro modernismo português: vanguarda e tradição. Lisboa: Publicações Europa-América, 1989.

ROCHA, Clara. Revistas literárias do século XX em Portugal. Lisboa: Imprensa Nacional/Casa da Moeda, 1985.

SACRAMENTO, Mário. Há uma estética neo-realista? Lisboa: Publicações Dom Quixote, 1968. 